\title{
Naturopathic Medicine on the Frontline of the COVID-19 Pandemic
}

\author{
Christopher Halldorson, ${ }^{1}$ ND
}

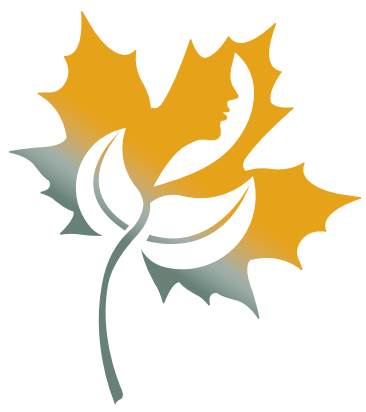

As a Naturopathic Doctor (ND), I was fortunate to spend the summer of 2021 providing naturopathic care on the frontline of the COVID-19 pandemic. I had the opportunity to work for a regional health authority in British Columbia, as part of British Columbia's COVID-19 immunization campaign. When the community immunization campaign accelerated, in March 2021, the Provincial Health Officer called on all qualified health professionals to contribute their skills to protect their communities and help end the COVID-19 pandemic by working as immunizers at mass immunization sites around the province. In BC, NDs, who hold Prescriptive Authority and are Immunization Certified through the BC Centre for Disease Control, are qualified to administer vaccines. Along with physicians, nurses (RN, LPN, RPN), and pharmacists, NDs are part of a core group of health professionals who can administer vaccines within their scope of practice. ${ }^{1}$ Due to the scale and urgency of the COVID-19 immunization campaign, additional professions were "deputized" to assist in the campaign by Special Order. ${ }^{2}$ This all-hands-on-deck approach had the goal of immunizing our population as quickly, safely, and effectively as possible. At the time of this writing, 3,837,848 people in $\mathrm{BC}$ have been fully immunized. ${ }^{3}$ I am proud to be one of the many healthcare providers in $\mathrm{BC}$ who contributed to this achievement, particularly because working on the immunization campaign followed the principles of naturopathic medicine.

Even before I was asked to join the COVID-19 immunization campaign, support for vaccines within the naturopathic community had been growing steadily. Currently, at least 156 NDs in BC have immunization certification, allowing them to provide vaccines to clients 12 years of age and older. ${ }^{4}$ Perhaps this is due to the increased acceptance that immunization should be considered naturopathic care, since it adheres to both the Naturopathic Therapeutic Order ${ }^{5}$ and the six principles of Naturopathic Medicine. ${ }^{6}$ The safety and efficacy profiles ${ }^{7-12}$ of the COVID-19 vaccines, while not perfect, are impressive and follow the principle of do no harm. As the COVID-19 pandemic becomes a "pandemic of the unvaccinated," unvaccinated individuals are more likely to be harmed through contracting the virus or being admitted to the hospital and/or ICU ${ }^{13}$ than by receiving a vaccine. Both the viral vector and mRNA vaccines capitalize on the healing power of nature to stimulate our self-healing mechanisms by generating an immune response to COVID-19 without community exposure. Once immunized, our own immune systems are able to identify and fight off the COVID-19 virus, preventing infections from occurring. As health-care providers, NDs play an important role in educating the public about the COVID-19 vaccines. The College of Naturopathic Doctors of British Columbia has recently reminded $\mathrm{BC}$ NDs of the important role of doctor as teacher and warned against participating in the spread of misinformation. ${ }^{14}$

A typical day at a COVID-19 immunization site would begin with a daily briefing for all the staff present. The briefing included identifying which vaccines and lot numbers were available that day, the number of appointments that had been scheduled, client eligibility for drop-in appointments, any update on the information, safety, efficacy, or adverse events of the COVID-19 vaccines, and of any special security considerations. Clients would be greeted by community volunteers, and office staff would ensure that each person was registered with the provincial immunization tracking system. While waiting for an immunizer, each client had access to take-home information ${ }^{15}$ about the risks of contracting COVID-19, and details about the protection offered by and possible adverse reactions to the COVID-19 vaccines. Finally, when a client met with an immunizer, they went through an initial assessment process to determine their suitability to receive a vaccine. Each client was provided accurate information about the possible risks associated with contracting COVID-19 and how the vaccines work to protect them. This was all part of the informed consent process and was presented in clear and plain language. Only after all questions were answered and consent was obtained was a vaccine administered. Afterwards, clients were monitored for $15 \mathrm{~min}$ utes to ensure no immediate allergic reactions occurred. By and large, this process was a simple and easy process for a client.

Although immunization is part of the scope of practice for NDs in $\mathrm{BC}$, it is rare for NDs to provide regular immunization services. This is because immunization is typically performed through the publicly funded health-care system and Canadian NDs practice as private health-care providers who work separate from the public system. The COVID-19 immunization campaign provided NDs with a rare opportunity to work within the public system. This

Correspondence to: Dr. Christopher Halldorson. E-mail: drhalldorson@gmail.com

To cite: Halldorson C. Naturopathic medicine on the frontline of the COVID-19 pandemic. CAND Journal. 2021;28(4):4-6. https://doi.org/10.54434/candj.94

Received: 01 October 2021; Accepted: 16 October 2021; Published: 15 December 2021

(c) 2021 Canadian Association of Naturopathic Doctors. For permissions, please contact candj@cand.ca. 
is of importance to the profession for a number of reasons. The first, and most important reason is that NDs helped to protect our communities from COVID-19, one shot at a time. Second, it improved public awareness of NDs and elevated the profession's profile as one that recognizes the scientific evidence supporting the safety and efficacy of the COVID-19 vaccines. ${ }^{16,17}$ Support for COVID-19 immunization is widespread throughout the medical community and it is formally recommended by the National Advisory Committee on Immunization, ${ }^{18,19}$ the College of Family Physicians of Canada, the Canadian Medical Association, the Royal College of Physicians and Surgeons of Canada, ${ }^{20}$ the Society of Obstetricians and Gynaecologists of Canada, ${ }^{21}$ and the Canadian Paediatric Society. ${ }^{22}$ Third, participation in the campaign builds bridges between the public system and the naturopathic profession. There is no better way to demonstrate the competency and proficiency of NDs to our medical colleagues than to work beside them as reliable partners. Fourth, it served a political purpose, as NDs showed that we can be called upon and work reliably when Canada's public health-care system needs assistance. Lastly, the COVID-19 immunization campaign is historic in scope. This was not just a Canadian effort but a global one to end the COVID-19 pandemic. By the end of September 2021, 6,136,962,861 COVID19 vaccine doses had been administered globally. ${ }^{23}$ The development and deployment of safe and effective vaccines to protect such a large proportion of the global population is truly a remarkable achievement in medicine, one to which NDs can proudly say that they have helped contribute.

As Canada progresses through the fourth wave of COVID-19 infections, and severe complications from the infection primarily affect the unvaccinated and under-vaccinated, NDs who participated in the COVID-19 immunization campaign should be aware of how working in the campaign has had immeasurably greater impact on our communities than not participating. We helped protect individuals and our communities. We helped our clients make informed choices on their health and we did it in a way that respects our naturopathic principles. Finally, we provided much-needed relief to our colleagues in the public health system and demonstrated that we support evidence-based preventative health measures.

\section{AUTHOR AFFILIATIONS}

${ }^{1}$ British Columbia Naturopathic Association, Vancouver, BC, Canada.

\section{ACKNOWLEDGEMENTS}

Not applicable.

\section{CONFLICTS OF INTEREST DISCLOSURE}

I have read and understood the CAND Journal's policy on conflicts of interest disclosure and declare that I have none.

\section{FUNDING}

None.

\section{REFERENCES}

1. College of Naturopathic Physicians of British Columbia Standards and requirements for Immunization Certification. Accessed September 23, 2021. https://cnpbc.bc.ca/for-registrants/resources/certification-requirements/ immunization
2. Regulated and unregulated health professionals SARS-CoV-2 Immunization - March 24, 2021. Accessed September 29, 2021. https://www2.gov.bc.ca/ assets/gov/health/about-bc-s-health-care-system/office-of-the-provincialhealth-officer/covid-19/covid-19-pho-order-ruhp-immunization.pdf

3. British Columbia Centre for Disease Control COVID-19 Dashboard. Accessed October 13, 2021. https://experience.arcgis.com/experience/ a6f23959a8b14bfa989e3cda29297ded

4. British Columbia Naturopathic Association Bulletin, fall 2021, p. 14.

5. Zeff J, Snider P, Myers S, Degrandpre Z. A hierarchy of healing: The therapeutic order. Pizzorno J, Murray M, ed. The Textbook of Natural Medicine, 4th Edition. Elsevier Editors; 2013, p. 18-33.

6. Association of Accredited Naturopathic Medical Colleges. The six principles of naturopathic medicine. Accessed September 23, 2021. https://aanmc. org/6-principles/

7. Polack FP, Thomas SJ, Kitchin N, et al. Safety and efficacy of the BNT162b2 mRNA COVID-19 vaccine. N Engl J Med. 2020;383:2603-26015. https://doi. org/10.1056/NEJMoa2034577

8. Frenck RW, Klein N, Kitchin N, et al. Safety, immunogenicity, and efficacy of the BNT162b2 COVID-19 vaccine in adolescents. N Engl J Med. 2021;385(3):239-250. https://doi.org/10.1056/NEJMoa2107456.

9. Baden L, El Sahly H, Essink B, et al. Efficacy and safety of the mRNA1273 SARS-CoV-2 vaccine. N Engl J Med. 2021;384:403-416. https://doi. org/10.1056/NEJMoa2035389

10. Ali K, Berman G, Zhou H, et al. Evaluation of mRNA-1273 SARS-CoV-2 vaccine in adolescents. $N$ Engl J Med. 2021. https://doi.org/10.1056/ NEJMoa2109522

11. Falsey AR, Sobieszczyk M, Hirsch I, et al. Phase 3 safety and efficacy of AZD1222 (ChAdOx1 nCoV-19) COVID-19 vaccine. N Engl J Med. 2021. https://doi.org/10.1056/NEJMoa2105290

12. Vaccine Safety. The BC Centre for Disease Control. Accessed September 29, 2021. http://www.bccdc.ca/health-info/diseases-conditions/covid-19/covid19-vaccine/vaccine-safety

13. The Government of Alberta. COVID-19 Alberta statistics - vaccine outcomes. Accessed October 12, 2021. https://www.alberta.ca/stats/covid19-alberta-statistics.htm\#vaccine-outcomes

14. College of Naturopathic Doctors of British Columbia Newsletter, September 2021

15. Healthlink BC File 124. Accessed September 23, 2021. https://www. healthlinkbc.ca/healthlinkbc-files/covid-19-vaccines

16. BC Centre for Disease Control. Two doses prevent about 95 per cent of COVID-19 hospitalizations: B.C. COVID-19 vaccine effectiveness results. Accessed October 12, 2021. http://www.bccdc.ca/about/news-stories/ stories/2021/covid-19-vaccine-effectiveness-results

17. Institut national de santé publique du Québec. Efficacité de deux doses de vaccin contre la COVID-19 chez les adultes Québécois vivant dans la communauté. Accessed October 12, 2021. https://www.inspq.qc.ca/ covid-19/vaccination/efficacite-2-doses

18. The National Advisory Committee on Immunization. Recommendations on the use of COVID-19 vaccines. Accessed October 12, 2021 https://www.canada.ca/content/dam/phac-aspc/documents/services/ immunization/national-advisory-committee-on-immunization-naci/ recommendations-use-covid-19-vaccines/recommendations-use-covid-19vaccines-en.pdf

19. The National Advisory Committee on Immunization. Recommendations on the use of mRNA COVID-19 vaccines in adolescents 12-17 years of age. Accessed October 12, 2021. https://www.canada.ca/en/public-health/ services/immunization/national-advisory-committee-on-immunizationnaci/recommendations-use-covid-19-vaccines/mrna-adolescents.html\#a6

20. The Canadian Medial Association. Canadian Medical forum supports the COVID-19 vaccines authorized in Canada. Accessed October 12, 2021. https:// policybase.cma.ca/en/viewer?file=\%2fdocuments\%2fPolicyPDF\%2fPD21-06. pdf $\#$ search $=$ covid $-19 \&$ phrase $=$ false

21. The Society of Obstetricians and Gynaecologists of Canada. SOGC statement on COVID-19 vaccination in pregnancy. Accessed October 12, 2021. https:// sogc.org/common/Uploaded\%20files/Latest\%20News/SOGC_Statement_ COVID-19_Vaccination_in_Pregnancy.pdf 
22. The Canadian Paediatric Society. COVID-19 vaccine for children. Accessed October 21, 2021. https://www.cps.ca/documents/position/covid-19-vaccinefor-children
23. World Health Organization. COVID-19 dashboard. Accessed September 29 2021. https://covid19.who.int 